\title{
Dasatinib-Induced Severe Hemorrhagic Colitis in Chronic Myeloid Leukemia
}

\author{
Murat KEKILLI ${ }^{1}$, Alpaslan TANOGLU ${ }^{2}$, Merih K. CAKAR ${ }^{3}$, \\ Guven GUNEY ${ }^{4}$, Ibrahim C. HAZNEDAROGLU ${ }^{5}$ \\ ${ }^{1}$ Hitit University Corum Training and Research Hospital, Department of Gastroenterology, Corum \\ ${ }^{2}$ GATA Haydarpasa Training Hospital, Department of Gastroenterology, Istanbul \\ ${ }^{3}$ Hitit University, Corum Training and Research Hospital, Department of Hematology, Corum \\ ${ }^{4}$ Hitit University, Corum Training and Research Hospital, Department of Pathology, Corum \\ ${ }^{5}$ Hacettepe University Faculty of Medicine, Department of Hematology, Ankara, TURKEY
}

\section{Dear Editor,}

Dasatinib is an orally administered, potent, secondline tyrosine kinase inhibitor which is used for treating imatinib resistant or intolerant chronic myeloid leukemia (CML) and Philadelphia chromosome-positive acute lymphoblastic leukemia. ${ }^{1}$ Dasatinib has several significant adverse reactions and gastrointestinal side effects. Risk factors for gastrointestinal bleeding including thrombocytopenia and advanced CML. ${ }^{2}$ Here, we report the case of a young male patient with $\mathrm{Ph}+$ chronic myeloid leukemia in the remissioned phase who was admitted to our gastroenterology clinic because of severe rectal bleeding, one year after the beginning of dasatinib use.

A 21-year-old male had been diagnosed with blastic phase of CML 3 years ago. During the follow-up, dasatinib (100 mg/day) was started nearly one year ago, because of resistance to imatinib. Dasatinib was continued as a maintenance therapy and during dasatinib therapy, he was admitted to our clinic with severe rectal bleeding. His physical examination was normal. Blood pressure was $110 / 75 \mathrm{mmHg}$ and heart rate was 76 beats per minute. The laboratory findings revealed a hemoglobin level of $13 \mathrm{~g} / \mathrm{dL}$, a white blood cell count of $8400 / \mathrm{mm}^{3}$, and a platelet count of $303000 / \mathrm{mm}^{3}$. His prothrombin time international normalized ratio value was 0.98 . Stool examination was negative for parasites and other pathogenic bacteria. Then he was prepared for total colonoscopy. From rectum to splenic flexure, colonoscopic findings were normal. But from splenic flexure to cecum, colonoscopic findings were compatible with severe hemorrhagic colitis (Figure 1-A). Multiple biopsies were taken from these mucosal areas. Histopathological examinations of biopsy specimens revealed hemorrhage, prominent lymphocytic inflammatory infiltrate including neutrophils, focal criptitis and lymphoid follicles in the lamina propria. Because of a well-known side effect, hemorrhagic colitis due to dasatinib was considered at the first step, dasatinib was stopped and no other medication was administered. He was followed up as an outpatient with recommends. 15 days later a control colonoscopy was performed and control colonoscopy was normal (Figure 1-B). Nilotinib (400 mg/day) was started as an alternative to dasatinib for CML treatment. Now, he is still alive and in complete remission.

Up to now, severe dasatinib-related hemorrhagic colitis, without thrombocytopenia or coagulation abnormalities, has been infrequently reported. In the literature, during dasatinib treatment, severe rectal bleeding due to acute colitis has been reported only in 1 acute lymphoblastic leukemia patient ${ }^{3}, 1$ acute myeloid leukemia patient ${ }^{4}$ and in 2 chronic myeloid leukemia patients. ${ }^{5}$ 


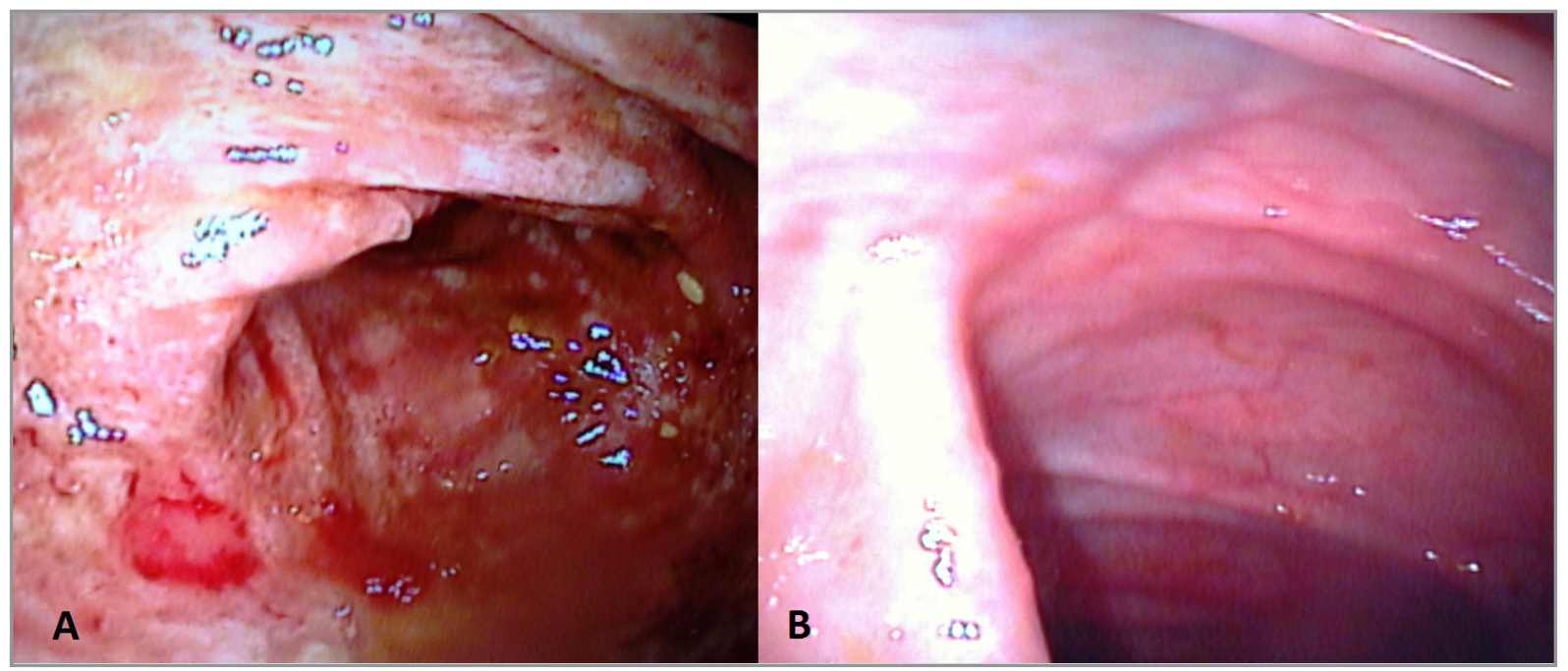

Figure 1-A. The colonoscopic findings were compatible with severe hemorrhagic colitis. 1-B. The control colonoscopy was normal

Original aspects of our case were; rectal bleeding was not related to thrombocytopenia or coagulation abnormalities, his clinical picture was not severe so we followed up our patient as outpatient because of his well being, and we just stopped the dasatinib and no other medication was administered and hemorrhagic colitis was healed dramatically.

\section{REFERENCES}

1. Li S. Src-family kinases in the development and therapy of Philadelphia chromosomepositive chronic myeloid leukemia and acute lymphoblastic leukemia. Leuk Lymphoma 49: 1926, 2008.

2. Quintas-Cardama A, Kantarjian H, Ravandi F, et al. Bleeding diathesis in patients with chronic myelogenous leukemia receiving dasatinib therapy. Cancer 115: 2482-2490, 2009.

3. Erkut M, Erkut N, Ersoz S, et al. A case of acute colitis with severe rectal bleeding in a patient with chronic myeloid leukemia after dasatinib use. Acta Haematol 123: 205-206, 2010.

4. Kmira Z, Nesrine BS, Houneida Z, et al. Severe hemorrhagic colitis in a patient with chronic myeloid leukemia in the blastic phase after dasatinib use. World J Gastrointest Pathophysiol 4: 59-62, 2013.
5. Sunami $Y$, Sato E, Ichikawa K, et al. Hemorrhagic colitis caused by dasatinib following cytomegalovirus enterocolitis in a patient with chronic myelogenous leukemia in the second chronic phase. Rinsho Ketsueki 52: 282-286, 2011.

\section{Correspondence}

Dr. Murat KEKILLI

Hitit Üniversitesi Tıp Fakültesi

Eğitim ve Araștırma Hastanesi

Gastroentoroloji Anabilim Dalı

Bacelievler Mahallesi

Camlık Caddesi No: 2

19100 CORUM / TURKEY

Fax: (+90-364) 2230300

e-mail: drkekilli@gmail.com 